\title{
CONTRIBUIÇÕES DA TEORIA DOS JOGOS, DA ESCOLHA RACIO- NAL E DO CONCEITO DE CAPITAL SOCIAL PARA O ESTUDO DA COOPERAÇÃO ENTRE SOCIEDADE E PODER PÚBLICO LOCAL
}

\author{
CONTRIBUTIONS FROM GAME THEORY, RATIONAL CHOICE, AND THE \\ CONCEPT OF SOCIAL CAPITAL TO THE STUDY OF COOPERATION \\ BETWEEN SOCIETY AND LOCAL PUBLIC POWER
}

\author{
CRistiano das Neves Bodart ${ }^{1}$
}

Recebido em: 29/05/2016 Aprovado em: 30/11/2016

\section{RESUMO}

Saber quais são as motivações que sustentam uma ação coletiva é uma questão bem presente na Sociologia Política e na Ciência Política. Buscando responder a essa indagação, frutificaram diversas teorias, como a Teoria da Escolha Racional, a Teoria da Mobilização dos Recursos e a Teoria do Confronto Político, cada uma delas contendo abordagens diferentes e explicações próprias. Diante disso, o presente artigo propõe-se a discutir, à luz das Teorias dos Jogos e da Escolha Racional e do conceito de Capital Social, quais são as motivações para a ação coletiva em parceria com o Poder Público local, tomando como estudo de caso uma ação coletiva ocorrida em 2011 no município de Piúma, localizado no sul do estado do Espírito Santo. Para isso, realizaram-se uma breve revisão de literatura e entrevistas com os envolvidos na ação coletiva. A incredibilidade nos políticos locais, o individualismo e a racionalidade foram fatores-chaves para a ação. Identifica-se que, embora inicialmente não houvesse um estoque significativo de Capital Social, a ação coletiva parece ter criado sinergia participativa e ampliado o estoque desse capital.

Palavras-Chave: Ação Coletiva; Racionalidade; Capital Social; Teoria dos Jogos; Teoria da Escolha Racional.

\begin{abstract}
Which motivations sustain public action is a question ever-present in Political Sociology and Political Science. The search to answer this question gave fruit to diverse theories, among them the Theory of Reasoned School, Rational Choice Theory, Resource Mobilization Theory, and Political Confrontation Theory, each one with different approaches and their own explanations. This article proposes to discuss, in light of Game Theory and Rational Choice and from the concept of Social Capital, which are the motivations for collective action in partnership with local government, using as a case study the collective action which took place in 2011 in the municipality of Piuma, located in the south of the state of Espirito Santo. A brief review of the literature and interviews with those involved in the collective action were carried out. The lack of faith in local politicians, individualism, and rationality were key to this action. Although initially there wasn't a significant stock of social capital, it is seen that the collective action seemed to have both created participative synergy and amplified the stock of this capital.
\end{abstract}

Keywords: Collective Action; Rationality; Social Capital; Game Theory; Rational Choice Theory. 


\section{Introdução}

Saber quais são as motivações que sustentam uma ação coletiva é uma questão bem presente na Sociologia Política e na Ciência Política. Buscando responder a essa indagação, frutificaram diversas teorias, como a Teoria da Escolha Racional, a Teoria da Mobilização dos Recursos e a Teoria do Confronto Política. Cada uma delas contém abordagens diferentes e explicações próprias.

A opção pelo uso de determinada teoria está relacionada a diversos fatores, dentre eles a sua presença nos estudos atuais [uma espécie de "onda da vez"] e sua capacidade explicativa. Contudo, há tentativas de mobilizar mais de uma teoria para analisar uma realidade ou fenômeno social, sendo essa opção ariscada e costumeiramente vista com inoportuna. Isso não significa que tais práticas não possam apresentar exitos, uma vez que teorias diferentes podem apontar para faces distintas do mesmo objeto e ampliar a sua compreensão, pois os objetos da Sociologia são, quase sempre, complexos. Aquino (2000, p. 29), por exemplo, ao analisar a Teoria Racional de Coleman e a Teoria Culturalista de Bourdieu, afirmou que, "afinal, se as duas estão corretas, são visões parciais da realidade; visões que, combinadas, permitem enxergar melhor do que cada uma isoladamente". Isso exposto, neste artigo, o intento é utilizar as potencialidades da Teoria do Jogos, da Teoria da Escolha Racional e do conceito de Capital Social, ainda que reconhecendo os perigos inerentes a esse caminho e o fato de tais teorias não se encontrarem em voga (ou na moda) no Brasil. Essa escolha se justifica por reconhecer que, embora com limitações explicativas, as teorias e conceito e questão apresentam potencialidades explicativas que carecem ser revisitadas.

Busca-se, assim, discutir, à luz das Teorias dos Jogos e da Escolha Racional e do conceito de Capital Social, as motivações para a ação coletiva que ocorre em parceria com o Poder Público local. Dessa forma, o presente artigo $^{2}$ tem como estudo de caso a ação coletiva que se desenvolveu em um bairro periférico (nominado "Morro dos Baianos") do município de Piúma, localizado no sul do estado do Espírito Santo. A experiência em análise consiste em um mutirão comunitário, elaborado em parceria com o Poder Público Municipal, para a pavimentação das ruas de toda essa comunidade.

Tal parceria se manifestou da seguinte forma: a Secretaria de Obras forneceu o material para a pavimentação, e os moradores a executaram com suas próprias mãos, formando mutirão. Foi observado que quase todos os moradores da comunidade, inclusive mulheres, jovens e crianças, participaram dessa ação coletiva. Tendo isso em vista, o presente artigo parte da seguinte indagação: o que motivou os indivíduos a participarem desse mutirão?

Em entrevista, os moradores que participaram do mutirão se mostraram informados quanto à obrigação do Poder Público local de realizar tais obras, uma vez que já pagam impostos relativamente altos, chegando à quarta maior arrecadação de Imposto Predial e Territorial Urbano (IPTU) per capita do estado do Espírito Santo (BORGES; VILLELA, 2010). Por que, mesmo assim, a comunidade participou de tal empreitada? Qual seria a "lógica" dessa ação?

A fim de buscar respostas satisfatórias para compreender a ação coletiva em torno de um bem público, especialmente no caso em estudo, julgamos adequado recorrer à Teoria dos Jogos e da Escolha Racional sob as bases do individualismo metodológico. Devido a algumas limitações explicativas encontradas, recorremos ao conceito de Capital Social, com o intuito de preencher essas lacunas. Assim, o referencial teórico deste trabalho centra-se nas

\footnotetext{
2 Este artigo teve uma versão menos acabada apresentada no GT 5, "Representação, Participação e Deliberação: desafios para a Teoria Politica no século XXI", do Seminário Nacional da Pós-Graduação em Ciências Sociais, ocorrido na Universidade Federal do Espírito Santo (UFES) em 2011.
} 
contribuições de Olson (1999), Hardin (1968), Coleman (1994), Boudon (1979), Elster (1994), Bourdieu (1980) e Fukuyama (1996).

Este artigo está dividido em duas seções, além desta introdução e das considerações finais. Na primeira seção, é realizada uma revisão de literatura, a fim de identificar em quais direções deveríamos seguir em nossa pesquisa. Já na segunda seção, é, inicialmente, apresentado o objeto em estudo, para logo após tratar dos resultados encontrados por meio de entrevistas fechadas objetivas e entrevistas desestruturadas abertas analisadas à luz das Teorias dos Jogos e da Escolha Racional, assim como a partir do conceito de Capital Social.

\section{Teorias dos Jogos e da Escolha Ra- cional e o conceito de Capital Social: contribuições teóricas}

Ao estudar uma parceria realizada entre o Poder Público local, mais especificamente com o Poder Executivo Municipal, e os moradores para a realização de mutirões objetivando a pavimentação de ruas, surge a seguinte indagação inicial: o que motiva esses moradores a participarem dessa ação coletiva? A fim de buscar respostas satisfatórias para essa situação, recorremos à Teoria da dos Jogos, à Teoria da Escolha Racional e ao conceito de Capital Social.

De modo geral, a ação coletiva consiste em uma ação comum que visa atingir fins partilhados. Porém, a simples ideia de que um grupo (ou uma classe) forma uma unidade de análise é refutada pela Teoria da Escolha Racional (TER). Para essa teoria, a ação coletiva é fruto dos interesses individuais compartilhados, questão que será tratada posteriormente. Primeiramente, vamos partir da seguinte indagação: os indivíduos tendem a participar de ações coletivas, especialmente em se tratando de bens públicos? A fim de aprofundarmos essa questão inicial, a qual desencadeará muitas outras pertinentes ao objetivo de nosso estudo, recorremos a diversos autores que apresentam significativas contribuições: Olson (1999), Hardin (1968), Coleman (1994), Elster (1994), Putnam (1994) e Ostrom (2008).

A TER é uma variante e um desenvolvimento da Teoria da Troca, estando diretamente ligada à Teoria dos Jogos e à Teoria das Redes. Dentre os teóricos da TER, destacam-se James Coleman, fundador dessa perspectiva analítica, e Mancur Olson (1999).

As premissas da TER são o individualismo, a otimização e o egocentrismo. Para essa teoria, embora existam ações coletivas, só os indivíduos agem. Esses indivíduos, por serem racionais, buscam otimizar seus ganhos, visando ao seu bem-estar.

Para Coleman, os estudos centrados nos indivíduos que compõem o grupo social podem ser mais frutíferos para a compreensão de todo o sistema. Por isso, Coleman é comumente denominado teórico do ator racional, uma vez que adotou o individualismo metodológico de Max Weber, em contraposição às ideias de Émile Durkheim. Nesse sentido,

[...] uma análise interna baseada nas ações e orientações de unidades em um nível mais baixo pode ser considerada mais fundamental, constituindo algo mais próximo de uma teoria do sistema de comportamento do que uma explicação que permanece no nível do sistema (COLEMAN, 1990, p. 4).

Assim, conforme Coleman,

Para um teórico [...] examinar como um fenômeno ganha existência, é preciso descer do nível macro-social para o nível dos atores, abandonando, pois, o paradigma da análise funcional por um paradigma que [...] contenha atores e uma teoria da ação $(1990$, p. 260$)$.

De acordo com Aquino (2001), Coleman afirma que uma teoria social deve possuir três momentos: 1) momento inteiramente situado no nível micro, 
em que ocorre a compreensão das ações sociais praticadas por indivíduos; 2) momento de transição do nível micro para o nível macro, em que se expõe como eventos individuais podem resultar em mudanças sociais; e 3) momento de transição do nível macro para o nível micro, em que se analisa a influência de aspectos da sociedade sobre os indivíduos. Assim, neste artigo, adotamos $\mathrm{o}$ individualismo metodológico, mais precisamente a TER, por sua colaboração para a compreensão dos motivos da cooperação em mutirões em parceria com o Poder Público local.

É importante evidenciar que Coleman está consciente de que as ações humanas têm muitos componentes irracionais (afetivos, tradicionais, moralmente motivadores etc.). Seu método baseado no individualismo tem sido alvo de muitas críticas, acusando-o, especialmente, de ser simplista. "No entanto, como diz Lafay, os críticos dessa opção metodológica não vêem que autores como Coleman adotam conscientemente uma estratégia reducionista, objetivando" (AQUINO, 2000, p. 21):

[...] reter o menor número possível de variáveis e representar do modo mais rudimentar suas interdependências a fim de deduzir conclusões fortes sobre a realidade. É, aliás, por essa razão que os construtores de modelos passam geralmente mais tempo pesquisando quais variáveis podem eliminar do que se interrogando sobre quais foram esquecidas (LAFAY, 1997, p. 233-234 Apud AQUINO, 2000, p. 21).

De acordo com Aquino (2000, p. 19), Coleman identifica a existência de três elementos básicos nos sistemas sociais: i) os atores e seus interesses; ii) os recursos necessários para satisfazer esses interesses; e iii) o controle sobre os recursos. A fim de empreitar seus estudos, Coleman constrói um modelo teórico simples do sistema social: sistemas com apenas dois atores, envolvidos em relações de autoridade e em relações de con- fiança. A partir da análise teórica desses atores, examina a demanda por normas sociais e a realização de normas sociais efetivas, culminando com a elaboração de uma Teoria do Capital Social, que tomaremos para esclarecer lacunas explicativas deixadas pelas Teorias dos Jogos e da Escolha Racional.

Elster (1994), ao tratar da Teoria da Escolha Racional, afirma que esta é instrumental, sendo as ações avaliadas e escolhidas como meios mais ou menos eficientes para atingir dado fim. Para esse mesmo autor, a escolha racional dos indivíduos objetiva encontrar os melhores meios para fins dados, sendo uma maneira de adaptar-se otimamente às circunstâncias, de modo a buscar, dentro das possibilidades, a melhor situação para si.

Elster (1994) aponta que a escolha racional não se caracteriza como um mecanismo infalível, pois um indivíduo racional escolhe com base em suas crenças, que lhe indicam a "melhor escolha". Ou seja, o processo pode ser racional, mas, mesmo assim, não atingir a verdade, já que "A crença é uma relação entre uma crença e aquilo sobre o que é a crença" (ELSTER, 1994, p. 41). Muitas vezes, a crença coloca o indivíduo diante de mais de uma possibilidade de escolha, até mesmo porque nem sempre nossas crenças são "preto no branco".

Elster apresenta basicamente três perigos relacionados à escolha racional: i) a existência de poucas evidências para efetivar a escolha ótima; ii) a demora para a tomada de decisão devido à busca de evidências, o que pode tornar a escolha atemporal, isto é, a ocasião para agir pode ter passado (como no caso de um médico que deve decidir se opera ou não seu paciente, em que a demora pela busca por evidências para basear a sua decisão pode fazer com que tal decisão não seja mais necessária no caso de o paciente não aguentar esperar e vir a óbito, por exemplo); e iii) quando a deliberação possuir um custo muito elevado em comparação com os resultados da escolha (como no caso de uma crian- 
ça que deverá esperar pela decisão judicial para saber se vai morar com seu pai ou sua mãe, em que o custo - problemas psicológicos, por exemplo - pago por ela pode ser superior ao benefício da decisão, mesmo que em condições ótimas).Uma lógica racional apontada por Elster (1994) está no conceito de "agir racionalmente", sendo este fazer o melhor para o próprio indivíduo. Para Elster, quando dois ou mais indivíduos interagem, eles podem produzir resultados muito piores do que se agissem sozinhos (nesse ponto, Elster recorre ao dilema dos dois prisioneiros). Assim, participar ou não de ações coletivas, como mutirões, perpassará por avaliações de custo-benefício. Elster ainda aponta que "a Teoria da Escolha Racional pode falhar através da indeterminação (1994, p. 49). Para ele, existem duas formas de indeterminação: i) pode haver mais de uma ação que seja igual e otimamente boa; e ii) pode não haver nenhuma ação que seja ao menos tão boa como todas as demais. "Quando a escolha racional é indeterminada, algum outro mecanismo deve preencher a brecha" (ELSTER, 1994, p. 53). Elster aponta que esse outro mecanismo pode ser o princípio de "satisfazer", ou seja, escolher algo que seja suficientemente bom, mesmo não sendo a escolha ótima. Dessa forma, podemos levantar duas hipóteses: i) o indivíduo pode participar do mutirão por julgar ser a melhor escolha a ser feita; e ii) o indivíduo pode escolher não participar por acreditar que existem outras opções tão boas ou melhores das quais participar.

Mancur Olson, na obra Lógica da Ação Coletiva (1990), busca explicar o comportamento de indivíduos racionais que se associam para a obtenção de algum benefício coletivo. Sua pretensão é apresentar uma alternativa à teoria tradicional de grupo. É importante notar que seu objeto de estudo é o comportamento de indivíduos racionais, tendo estes o objetivo de obter benefícios coletivos que se convertam em vanta- gens individuais. Para desenvolver sua teoria, Olson apoia-se no conceito de benefício coletivo como um "benefício indivisível", ou seja, aquele que uma vez consumido por um grupo não pode ser negado a uma pessoa desse grupo, mesmo que tal indivíduo não tenha se dedicado à sua obtenção.

Segundo Olson (1990), o interesse comum dos membros de um grupo pela obtenção de um benefício coletivo nem sempre é suficiente para levar cada um deles a contribuir para a obtenção desse benefício. Existem circunstâncias em que o indivíduo do grupo, sabendo que o benefício coletivo não lhe será negado, independentemente de sua participação ou não (por se tratar de um bem coletivo), tenderá a se escusar, a fim de ampliar seu bem-estar, deixando que os demais paguem pelos custos de sua obtenção. Assim, reduz a zero o seu custo (o que convencionalmente é chamado de free rider - bilhete gratuito) e desfruta do benefício gerado. Seguindo esse raciocínio, cada um dos membros do grupo estaria tentado a deixar aos outros o cuidado de pagar pelos custos da ação coletiva. Torna-se evidente, nessas condições, que a pura expectativa generalizada acarretará um "efeito perverso" (BOUDON, 1977): se todos os membros optarem pela estratégia do free rider, o bem coletivo deixará de ser obtido.

A decisão de todo indivíduo racional sobre se irá ou não contribuir para a obtenção do benefício coletivo depende, na concepção de Olson (1990), das seguintes condições: os custos da ação devem ser inferiores aos benefícios alcançados, uma vez que a participação do grupo na ação coletiva implica, para cada um dos membros do grupo latente, certos custos, como tempo, dinheiro, etc.

Outro fator apresentado por Olson (1990) que influencia a ação coletiva é o tamanho do grupo. Olson (1990) argumenta que grupos menores tendem a ter maior adesão de seus membros, o que ocorre por vários fatores, como o fato de o benefício ser dividido por um 
número igualmente reduzido de participantes, sendo o benefício recebido significativo a cada membro. Para Olson (1990), grupos grandes são mais suscetíveis a não atingirem seus objetivos, por ser o benefício diluído a tal ponto que os custos da participação excedem os benefícios alcançados, desestimulando o indivíduo. Outro motivo é que a não participação do indivíduo não apresenta grande impacto sobre o resultado, como geralmente ocorre em grupos pequenos. Assim, grupos grandes tendem a ter indivíduos não atuantes, mas que serão beneficiados pelos resultados, uma vez que se trata de benefícios coletivos, daí a necessidade de algum tipo de coerção sobre o não participante ou da existência de benefícios exclusivos incentivos coletivos - para aqueles que participarem da ação. Um oferecimento paralelo de bens individuais, não necessariamente materiais, é um meio para estimular os recalcitrantes. Os incitamentos morais e "solidários" desempenham, na realidade, um papel importante na emergência da ação coletiva. Agir coletivamente em uma coletividade, em que predominam laços e redes de solidariedade, confiança e amizade, pode constituir uma obrigação moral para o indivíduo, podendo tornar-se igualmente, para ele, um prazer. Sob essas condições, é a não participação que será custosa, pois poderá pôr em questão a imagem e a estima que o indivíduo tem de si próprio. Para Oberschall (1973), a ausência de laços e a decomposição das redes de interação são obstáculos importantes à mobilização (ou não incentivo à participação).

Em outras palavras, o estoque de Capital Social pode influenciar o engajamento ou não dos indivíduos. Por isso, lançamos mão do conceito de Capital Social, a fim de ampliar a compreensão do fenômeno social em estudo. O conceito de Capital Social, embora não seja novo, ganhou notoriedade a partir da obra de Robert Putnam, publicada em 1993: $M a-$ king Democracy Work: Civic Tradition in Modern Italy (D'ARAUJO, 2003, p. 11). Inicialmente, em Hanifan (1916), o conceito havia sido definido como "um conjunto de relações sociais marcadas pela boa vontade, camaradagem e simpatia, atributos muito próximos do goo$d$ will utilizado para definir as relações públicas na sua origem" (HANIFAN, 1916 Apud D'ARAUJO, 2009, p. 3536). Bourdieu, em 1980, sistematizou no campo da Sociologia o conceito. De acordo com Matos (2009, p. 35), Bourdieu, em seu artigo Le capital social: notes provisoires, definiu Capital Social como "o conjunto de recursos atuais e potenciais que estão ligados à posse de uma rede durável de relações mais ou menos institucionalizadas de interconhecimento e inter-reconhecimento".

O conceito de Capital Social utilizado por Bourdieu (1980) é de grande contribuição para esta pesquisa, pois o Capital, em seu caráter utilitário, é um "ativo" social adquirido de forma desigual, uma vez que as redes sociais nas quais estão inseridos os indivíduos não oferecem as mesmas condições para obtenção das mesmas quantidades e qualidades desse capital (BOURDIEU, 1980, p. 2). Além das contribuições de Bourdieu, apropriamo-nos das conceituações de Putnam (1993 [1996]) e de Fukuyama (2000) sobre o Capital Social, as quais, a nosso ver, não são contraditórias, mas complementares.

Para Putnam (1996), o conceito de Capital Social "diz respeito a características da organização social, como confiança, normas e sistemas, que contribuam para aumentar a eficiência da sociedade, facilitando as ações coordenadas" (p. 177). Para esse autor, o Capital Social é, assim, uma herança histórica, ou seja, é produzida e ampliada conforme as experiências dos grupos. Trata-se de um capital que, quanto mais utilizado, mais a comunidade cívica o possuirá, ou seja, quanto mais se usa o Capital Social, mais se adquire. Dessa forma, a confiança é geradora de confiança, sendo base para a cooperação. 
Putnam afirma que o Capital Social possibilita a existência de laços comunitários fortes capazes de garantir a ação coletiva, levando as pessoas a participem ativamente do processo de construção da democracia por via de mecanismos não convencionais de envolvimento político (BAQUERO; SOUZA; SCHERER, 2009, p. 9). Nessa direção, formulamos uma de nossas hipóteses de pesquisa: um maior estoque de Capital Social propicia maior cooperação.

Uma vez que o indivíduo racional adquiriu Capital Social, não desejará perder a confiança obtida. A regra de reciprocidade está relacionada, segundo Putnam, com o que dizia Cícero no tempo de César: "nenhum dever é mais importante do que retribuir um favor".

De acordo como Fukuyama (2000 apud HIGGINS, 2005), o Capital Social é produto espontâneo dos jogos repetitivos do dilema do prisioneiro. Uma vez que o jogo se repete, a simples estratégia de pagar na mesma moeda (cooperação por cooperação, traição por traição) conduzirá os jogadores racionais a um resultado de cooperação, produzindo, assim, o Capital Social, uma vez que os indivíduos tenderão a apostar em sua reputação de honestidade e de integridade.

Fukuyama (1996, p. 41) define Capital Social como "capacidade que decorre da prevalência de confiança numa sociedade ou em certas partes dessa sociedade". Para esse autor, o Capital Social pode estar incorporado no menor grupo social (a família), no maior de todos os grupos, a nação, assim como nos grupos intermediários (FUKUYAMA, 1996, p. 41).

Para Furlanetto (2008), o conceito de Capital Social pode ser agrupado em duas correntes:

[...] a primeira, comum entre os sociólogos, reforça a idéia de que as ações individuais podem ser fortalecidas por meio da participação dos mesmos em redes sociais, em intera- ções diretas e indiretas com os outros atores da rede, e a relacionam aos recursos e benefícios potenciais que um ator detém, por possuir ou participar de uma rede sólida e durável de relações pessoais (BOURDIEU, 1985; COLEMAN, 1988; PORTES, 1998); na segunda corrente, a da preferência dos cientistas políticos, o capital social é visto como uma parte significativa das relações e laços internos que caracterizam as bases da ação coletiva e garantem-lhe a coesão necessária para atingir os resultados esperados (PUTNAM, 1993, p. 179; FUKUYAMA, 1995, p. 377; LOCKE, 1995, p. 3; WOOLCOCK, 1998) (FURLANETTO, 2008, p. 62).

Para outros autores, o conceito de Capital Social mantém-se em uma perspectiva instrumental, "pois estaria baseada no proveito que os indivíduos obtêm ao participarem em estruturas sociais" (PONTES, 2000 apud HIGGINS, 2005, p. 31). Com base nas contribuições apresentadas em torno do conceito de Capital Social, buscamos, a partir de um estudo de caso, identificar se diferentes níveis de Capital Social apresentam alguma correlação com a participação ou não na ação coletiva em formato de mutirão, estabelecida em parceria com o Poder Público.

Reconhecemos, contudo, as limitações inerentes à tentativa de mensurar o Capital Social. Essa dificuldade não é exclusiva desta pesquisa, pois "várias metodologias têm sido propostas, especialmente por economistas, porém nada ainda parece consensual o bastante" (D'ARAUJO, 2003, p. 27). A maior parte dos trabalhos tem buscado, sem muito rigor, medir os resultados do Capital Social, mas não o Capital Social em si, o que também não é nosso objetivo.

Para pensarmos o estudo de caso que nos propomos, adotamos a perspectiva da ideia de que "as ações individuais podem ser fortalecidas por meio da participação dos mesmos [dos indivíduos] em redes sociais, em interações 
diretas e indiretas com os outros atores da rede, e a relacionam aos recursos e benefícios potenciais que um ator detém, por possuir ou participar de uma rede sólida e durável de relações pessoais", como defendido por Bourdieu, Coleman e Portes (FURLANETTO, 2008, p. 62).

\section{0 dilema da ação coletiva: um estudo de caso sob as contribuições da Teoria dos Jogos, da Teoria da Escolha Racio- nal e do conceito de Capital Social}

Buscamos, neste trabalho, discutir, à luz das Teorias dos Jogos e da Escolha Racional e do conceito de Capital Social, as motivações que levaram os indivíduos a participar de mutirões em parceria com o Poder Público local. O estudo de caso centra-se na ação coletiva realizada em 2011. Tal ação ocorreu em bairro periférico de Piúma, Espírito Santo, denominado Morro dos Baianos. Trata-se de uma comunidade com apenas seis ruas (Rua Santa Brígida, São José, Glória, do Café, Pedro e Maurício), totalizando cerca de quatro mil metros de extensão (em termos de comprimento), todas pavimentadas nessa ação coletiva comunitária.

Piúma tem aproximadamente 16 mil habitantes e localiza-se na Região Litoral-Sul, a cerca de $90 \mathrm{~km}$ de distância da capital do estado, Vitória. Trata-se do menor município do estado em tamanho territorial. Devido às ofertas de emprego originadas com as ampliações, nos últimos dez anos, das usinas de pelotização de ferro da empresa Samarco Mineração S/A e à estagnação econômica do sul da Bahia (o que se deu a partir da década de 1970), especialmente ligada à produção de cacau, muitos emigraram para as proximidades da mineradora. Mesmo estando a cerca de $20 \mathrm{~km}$ de distância da empresa de pelotização de minério de ferro, localizada no norte do município vizinho (Anchieta), Piúma acabou recebendo muitos desses imigrantes, dando origem a alguns bairros periféricos e ocupados de forma desordenada, dentre eles o Morro dos Baianos.

Este estudo focaliza a participação da comunidade de Morro dos Baianos no mutirão realizado para a pavimentação das ruas do bairro. Tal pavimentação foi parte de um projeto do executivo municipal, denominado "Plano Municipal de Calçamento de 60 ruas" (PMC60). De acordo com o Secretário Executivo de Desenvolvimento desse município, o projeto foi lançado pelo prefeito no fim de 2010, com a pretensão de calçar 60 ruas em toda a cidade.

Tal plano chamou a atenção da população local por se tratar de um fato ainda não presenciado no município: o volume relativamente grande de pavimentações. Mas o que tornou esse projeto, de certa forma, evidenciado na mídia capixaba foi a proposta do método do trabalho: mutirão em parceria com a população residente, a qual participaria diretamente com a mão de obra. Nessa parceria, a Secretaria Municipal de Obras do município ofereceu aos moradores interessados os equipamentos e os materiais, além de coordenar os trabalhos para as pavimentações. O projeto alcançou seu objetivo, calçar praticamente todo o bairro Morro dos Baianos, ainda que tenha sido alvo de muitas críticas pela falta de drenagem e por ter sido realizado com a mão de obra dos moradores.

Segundo o então Secretário de Desenvolvimento do Município de Piúma, não se tratava de uma ideia nova. $\mathrm{O}$ mutirão já havia ocorrido em gestão anterior; porém, naquele momento, estaria acontecendo com maior vigor e com modelagem diferente: no modelo anterior, a população sedia o material, e a prefeitura executava a obra; agora a proposta era o inverso.

Para o presente estudo de caso, foram realizadas entrevistas quantitativas e qualitativas com os moradores das áreas onde ocorreram os mutirões. As entrevistas foram aplicadas junto a 20 
moradores chefes de domicílio, a dois representantes do poder público e ao presidente da Associação de Moradores do bairro. $\mathrm{O}$ número de moradores entrevistados limitou-se a 20 devido ao pequeno número de famílias residentes no bairro, compreendendo cerca de $10 \%$ dos domicílios.

Buscamos identificar se a ação coletiva estudada constituía uma unidade de análise ou, como afirma a TER, se os indivíduos compartilhavam interesses individuais. Identificamos que se trata de indivíduos que têm em comum alguns aspectos, como uma renda e escolarização baixa, mas interesses, valores e opiniões diversas. Tratava-se, assim, de um grupo que não poderia ser analisado como uma unidade, motivo pelo qual foram realizadas entrevistas com diversos chefes de domicílio, com representantes do Poder Público e com o presidente da Associação de Moradores do bairro.

Uma indagação inicial realizada neste artigo era: os indivíduos tendem a participar de ações coletivas, especialmente quando se trata de bens públicos? A fim de buscar uma resposta para essa pergunta, perguntamos aos moradores: "Se um projeto da comunidade não the beneficia diretamente, mas pode beneficiar outras pessoas do seu bairro, o senhor contribuiria para esse projeto?". Notamos que $95 \%$ dos entrevistados responderam que ajudariam nessa nova ação coletiva. Mas, ao perguntar "Nos últimos anos, antes desse mutirão, o senhor tentou resolver algum problema local do bairro/comunidade junto com outras pessoas?", identificamos que 55\% responderam afirmativamente. Confrontamos esses dois resultados e chegamos à seguinte indagação: por que praticamente todos afirmam estarem dispostos a participar de uma ação coletiva para provimento de bens públicos, mas apenas pouco mais da metade dos entrevistados já havia anteriormente participado de uma ação coletiva dessa natureza?

Recorrendo a Olson, poderíamos pensar que, por se tratar de bens públi- cos, quase metade dos entrevistados não havia participado? A resposta parece ser positiva. Mas como explicar o fato de que eles se dispõem a participar de uma futura ação coletiva? Talvez Olson esteja certo, porém não previu o que Putnam apontou: a ação coletiva, quando bem-sucedida, gera Capital Social. Acreditamos que a experiência de agir de forma coletiva gerou maior confiança para uma posterior mobilização, uma vez que a confiança parece ter se ampliado, tornando as regras do jogo mais claras em uma segunda rodada.

Buscamos identificar, ainda, se os entrevistados se arrependeram de ter participado do mutirão e identificamos que todos os entrevistados afirmaram não ter se arrependido. A participação marcada pelo sucesso na obtenção dos objetivos parece ter sido não só animadora, mas também pedagógica.

Em entrevista desestruturada com os moradores, observamos que todos estavam satisfeitos com a ação coletiva. Na pesquisa quantitativa, averiguamos que $50 \%$ dos entrevistados afirmaram não estarem satisfeitos com o resultado material. Notamos, dessa forma, que a satisfação em ter agido coletivamente para minimizar um problema da comunidade foi superior à satisfação do resultado material, uma vez que, conforme apontaram os entrevistados, o projeto de execução realizado pela Prefeitura deveria ser diferente. A maior reclamação estava relacionada ao fato de tais ruas serem pavimentadas sem sistema de drenagem.

Como já apresentado, a TER tem como princípio o individualismo, a otimização e o egocentrismo. Estariam essas três características presentes na comunidade analisada? Para atingir uma resposta satisfatória, realizamos algumas perguntas aos entrevistados. Algumas das perguntas e os resultados mais interessantes são apresentados na Tabela 1, exposta a seguir. 
Tabela 1 - Principais resultados encontrados ligados à averiguação de princípios individualistas, de otimização e de egocentrismo*

\begin{tabular}{|c|c|c|c|}
\hline $\begin{array}{l}\text { Pensando na qua- } \\
\text { lidade dos serviços } \\
\text { públicos, o valor dos } \\
\text { impostos que o se- } \\
\text { nhor paga é? }\end{array}$ & $\begin{array}{l}\text { Atualmente o cr- } \\
\text { nhor participa } \\
\text { algum grupo ou or- } \\
\text { ganização? }\end{array}$ & 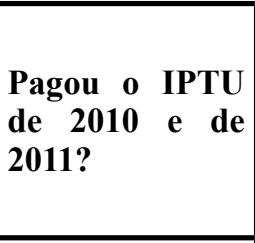 & $\begin{array}{l}\text { Nos últimos anos, o } \\
\text { senhor tentou resolver } \\
\text { algum problema local } \\
\text { do bairro/comunidade } \\
\text { junto com outras pes- } \\
\text { soas? } \\
\end{array}$ \\
\hline $\begin{array}{l}90 \% \text { responderam que } \\
\text { consideram muito alto } \\
\text { ou alto. }\end{array}$ & 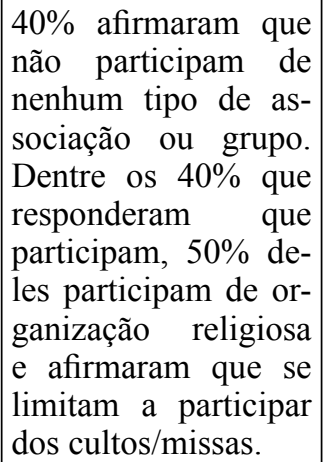 & $\begin{array}{lr}\text { Apenas } & 20 \% \\
\text { afirmaram } & \text { que } \\
\text { sim. } & \end{array}$ & $\begin{array}{l}\text { Apena } 55 \% \text { responde- } \\
\text { ram positivamente. }\end{array}$ \\
\hline
\end{tabular}

Fonte: elaborada pelos autores com base nas entrevistas realizadas.

*Alguns entrevistados não quiseram ou não souberam responder.

A partir da Tabela 1, observamos alguns indicadores ligados aos princípios individualistas, de otimização e de egocentrismo, como apontado pela TER. Notamos que a maior parte dos entrevistados não paga IPTU (importante destacar que todos afirmaram serem donos legais dos imóveis onde residem), buscando, assim, maximizar seus benefícios. Embora não paguem IPTU, $90 \%$ deles o consideram abusivo. Foi possível observar que tais moradores, em sua grande maioria, não se engajam em questões coletivas relacionadas à busca de provimento de bens públicos. Pouco mais da metade (55\%) já havia realizado algum tipo de ação coletiva pontual e esporádica para solucionar problemas de sua comunidade. Tais resultados fornecem um forte indício de que esses atores sociais agem segundo os princípios propostos pela TER.

Buscamos identificar, também, se os perigos apresentados por Elster (1994) se manifestaram nos mutirões em estudo. Apenas a existência de poucas evidências para efetivar a escolha ótima foi observada, já que somente
$55 \%$ dos entrevistados afirmaram ter conhecimento do projeto antes de sua aplicação e $50 \%$ afirmaram que o projeto poderia ter sido diferente. Talvez, como afirmaram alguns moradores, se a população soubesse que não iria ser feito as galerias de escoamento da água da chuva, teria pressionado o Poder Público local a modificar o projeto.

Afirmam os teóricos da TER que os indivíduos tendem a maximizar seus benefícios, mas, quando não é possível alcançar uma situação ótima, ao menos buscam uma situação boa. Tal apontamento teórico foi observado na prática.

Ao entrevistar os moradores do bairro do Morro dos Baianos, identificamos que tais indivíduos possuíam um dilema e estavam, de certa forma, conscientes da situação. Podemos, ainda que de forma simplista, assim descrever esse dilema: o Poder Público tem a obrigação de pavimentar as ruas, mas, embora há anos venha prometendo pavimentá-las, nunca o fizera. Havia agora uma proposta concreta para pavimentar as ruas por meio da parceria, tendo, assim, custos significativos aos 
moradores. Dessa forma, estavam diante de duas possibilidades: i) uma incerteza, a de que o Poder Público, exclusivamente, viria a pavimentar as ruas, cumprindo as promessas anteriores (o que seria a situação ótima); e ii) aceitação da oferta concreta da prefeitura de fazer uma parceria. As duas possibilidades desdobravam-se em três situações possíveis: uma situação ótima, uma situação trágica e uma situação subótima. Em situações como essa, a Teoria dos Jogos corrobora ao fornecer uma parábola recorrentemente utilizada: o dilema do prisioneiro.

O dilema do prisioneiro costuma ser amplamente adotado como colaborador na compreensão de conflitos entre os interesses particulares e o interesse coletivo para casos em que a conduta é racionalmente orientada (REIS, 2000, p. 104). Tal dilema pode ser assim apresentado: dois homens são acusados - sem provas - de um crime e ambos são, separadamente, interrogados na delegacia. Se os dois negarem poderão sair inocentados. Mas, se um deles confessar o crime, terá sua pena reduzida pela metade, enquanto que o outro será condenado a pagar toda a pena. A incerteza de que o comparsa irá negar as acusações levará o indivíduo racionalmente a optar por uma situação mais certa: confessar o crime e ter sua pena reduzida. Assim, a situação subótima (a pena reduzida) será escolhida por ser a situação ótima (ser inocentado) duvidosa, em detrimento de ser condenado a pagar a pena completa (a tragédia). Nesse sentido,

dois indivíduos que têm a possibilidade de ganho conjunto através da adoção de determinada linha de ação inscrita entre as alternativas que deparam são levados, dado os estímulos existentes à ação guiada pelo interessa particular, a adotar racionalmente estratégias que redundam $\mathrm{m}$ desastre para ambos (REIS, 2000, p. 105).
No caso do dilema que envolvia os moradores do Morro dos Baianos, a situação ótima seria a Secretaria de Obras realizar a pavimentação do bairro, como já havia prometido anteriormente. Assim, os moradores teriam um benefício com custo reduzido (limitado às obrigações fiscais). O problema é que tal situação ótima era incerta e poderia finalizar em uma situação trágica.

A situação trágica seria a não realização da pavimentação das ruas do bairro. Contudo, havia uma terceira possibilidade, com maiores garantias, mas também com maiores custos aos moradores. Essa terceira possibilidade ocuparia uma posição intermediária entre as duas situações anteriores apresentadas. Tratava-se da realização da pavimentação das ruas do bairro por meio de parceria entre comunidade e Poder Público local, como já apresentado. Essa seria a situação subótima, pois é marcada por maiores custos, diferentemente da situação ótima, e pela certeza da realização, diferentemente da situação trágica.

Poderiam os indivíduos não participar da ação coletiva por não ser a sua lógica compatível com a lógica da ação coletiva. Boudon afirma que:

A comunidade de interesse, mesmo sendo um dado evidente para todos, não basta para provocar a ação comum que permita promover o interesse de todos. A lógica da ação coletiva e a lógica da ação individual não são a mesma coisa (1979, p. 37).

Elster ainda aponta que "a teoria da escolha racional pode falhar através da indeterminação" (ELSTER, 1994, p. 49). Para ele, existem duas formas de indeterminação: i) pode haver mais de uma ação que seja igual e otimamente boa; e ii) pode não haver nenhuma ação que seja ao menos tão boa como todas as demais. "Quando a escolha racional é indeterminada, algum outro mecanismo deve preencher a brecha" (ELSTER, 
1994, p. 53). Elster aponta que este outro mecanismo pode ser o princípio de "satisfazer", ou seja, escolher algo que seja suficientemente bom, mesmo não sendo a escolha ótima. Dessa forma, podemos levantar duas hipóteses: i) o indivíduo pode participar do mutirão por julgar ser a melhor escolha a ser feita; e ii) o indivíduo pode escolher não participar por acreditar que existem outras opções tão boas ou melhores do que participar do mutirão.

Quais teriam sido as motivações para que a ação social ocorresse no Morro dos Baianos? Por que então os indivíduos da comunidade optaram pela situação subótima? Estariam os indivíduos motivados pela escolha racional marcada pela avaliação custo-benefício? Elster (1994) aponta que tal escolha não se caracteriza como um mecanismo infalível. Ou seja, o processo pode ser racional, mas mesmo assim não atingir a verdade. "A crença é uma relação entre uma crença e aquilo sobre o que é a crença" (ELSTER, 1994, p. 41). Teriam os indivíduos da comunidade realizado a escolha errada?

Buscamos identificar se os perigos apresentados por Elster e North estiveram presentes no processo de decisão da comunidade. São eles: i) a existência de poucas evidências para efetivar a escolha ótima - poucos moradores tiveram acesso às informações de que a prefeitura havia aprovado um orçamento relativamente elevado destinado à pavimentação de ruas, o que seria um indicador forte de que, com parceria ou não da comunidade, a obra seria realizada; ii) a demora para a tomada de decisão devido à busca de evidências poderia tornar a escolha atemporal - as obras estavam previstas para o fim do ano de 2010 e o ano de 2011. Uma demora em aceitar a proposta poderia fazer com que o cronograma fosse preenchido pela demanda de outros bairros.

Com relação à colaboração da Teoria dos Jogos para a compreensão do presente estudo de caso, recorremos à argumentação de North. Para esse autor, "a cooperação é difícil de ser sustentada quando o jogo não se repete (ou tem um fim), quando falta informação sobre os outros jogadores e quando há um grande número de jogadores". A situação dos moradores do Morro dos Baianos era de um jogo repetido, em que promessas de pavimentação das ruas eram realizadas anualmente pelos políticos locais, mas não cumpridas. Havia agora um novo jogo cujas regras não estavam ainda claras devido ao fato de ser a primeira rodada. Os moradores, conhecendo o jogo anterior, optaram em apostar no novo jogo, embora a participação social não fosse tão fácil e simples de ser mobilizada.

Identificamos que a comunidade era composta de grupos com perfis diferentes em relação ao engajamento participativo. Elster (1994) colabora com este trabalho apontando que acredita que a maior parte da cooperação se deve a motivações não egoísticas de uma espécie ou de outra (ELSTER, 1994, p. 159). Para Elster, as motivações para a participação são variadas, coexistem e reforçam umas às outras. Para tanto, ilustra o que acredita ser um caso típico de ação coletiva: os envolvidos na ação coletiva (os não egoístas) são os kantianos, caracterizados por querer fazer aquilo que seria melhor se todos o fizessem. Outro grupo seriam os utilitaristas, marcados por desejar prover o bem comum. Por fim, afirma Elster que alguns são motivados pela norma de equidade, já que "não querem andar de carona na cooperação dos outros, mas também não querem cooperar quando poucos outros o fazem" (ELSTER, 1994, p. 159).

Para Elster (1994, p. 159), nunca há muitos kantianos, mas, se o número de utilitaristas for significante, isso motivaria os kantianos a agirem, e, consequentemente, os que são motivados pela norma de equidade acabariam participando. A ilustração de Elster contribui, ainda que de forma limitada, para a compreensão do caso em estudo. Ob- 
servamos que o número de indivíduos da comunidade do Morro dos Baianos que deram início à busca de parceria (identificados como utilitaristas) era pequeno em relação ao tamanho da população do bairro, mas suficiente para motivar os demais kantianos e aqueles movidos pela norma de equidade. Embora observada tal situação, não é possível afirmar que o grupo que tomou a iniciativa seja altruísta. Por que desejariam seus integrantes promover o bem comum? Seriam altruístas ou estariam movidos pela racionalidade em busca de benefícios individuais?

Segundo Boudin (1979, p. 44), a participação pode ser um prazer em si mesmo, para quebrar o tédio quotidiano ou dar ao ator um sentimento de importância. No caso em estudo, foi observado que aqueles que não se enquadravam nas classificações de Elster (1994), a saber, os kantianos, os utilitaristas e os movidos pela regra da equidade, teriam participado por lazer, uma vez que tal prática não é tão comum na comunidade. Como disse um dos entrevistados: "Tudo era festa. Havia muita gente".

Um ponto identificado nesta pesquisa se relaciona ao tamanho dos grupos envolvidos, como apontou Olson (1990). Os entrevistados mencionaram a facilidade de coordenar o mutirão devido ao fato de o grupo ser pequeno (apenas os moradores diretamente beneficiados). Mas, ao contrário do que afirma Olson, a facilidade para a participação de todos não esteve ligada ao fato de o indivíduo ser coagido pelos demais, sendo este fiscalizado de perto. $\mathrm{O}$ que foi identificado é que a participação gerou participação, isto é, tendo a certeza da participação dos demais, o indivíduo via-se em um jogo de cartas abertas: não havendo desertores, criou-se uma sinergia em torno da participação. As dificuldades existem não apenas devido ao tamanho do grupo, mas também devido ao cálculo custo-benefício que fazem os indivíduos (HARDIN, 1982 Apud NORTH, 1990, p. 13), como já demonstrado por meio do dile- ma do prisioneiro, e à existência ou não de coercitividade.

North (1990, p. 14) levanta uma indagação-chave para este estudo: sob que condições a cooperação voluntária pode existir sem a solução hobbesiana da imposição de um Estado coercitivo para criar soluções cooperativas? Ele destaca que, historicamente, "o crescimento das economias ocorreu dentro da moldura institucional de políticas coercitivas bem desenvolvidas". Compreender a motivação dos atores é algo mais complicado do que presume a teoria que trata do tema.

Para North (1990), é importante destacar o papel das instituições nas escolhas dos indivíduos, pois elas alteram o preço pago pelos indivíduos e embutem suas ideias, suas ideologias e seus dogmas, podendo influenciar as escolhas dos indivíduos. Cabe igualmente destacar que o ambiente é utilizado pelo indivíduo a fim de entender as circunstâncias que podem determinar suas escolhas. Outro ponto importante para a tomada de decisão, segundo North, é o processamento incompleto de informações. Para North, "essa incerteza não só produz comportamento previsível, como também é a fonte subjacente das instituições". Devido a tal situação, são criadas as instituições que têm o papel de reduzir as incertezas envolvidas na interação humana.

No caso da ação coletiva realizada no Morro dos Baianos, a Associação dos Moradores foi uma peça fundamental para o início do processo. Tal associação vem atuando há alguns anos sobre os moradores, buscando influenciá-los a participar de ações coletivas. Frente à incerteza, a Associação desempenhou o papel de "assegurador" de que a ação seria realizada até o final, pois essa, acreditavam os moradores, estaria na incumbência de cobrar a contrapartida do Poder Público, bem como um maior engajamento da comunidade.

Para North (1990, p. 15), é a “a medição mais o alto custo da aplicação 
que juntos determinam o custo de transação". Os custos são agravados pela falta de informação, uma vez que o indivíduo terá de despender maiores custos com o policiamento dos agentes e com a criação de códigos de condutas internamente aplicados ou de sanções societais ou, ainda, com a existência de uma terceira parte coercitiva. No caso da ação coletiva desenvolvida no Morro dos Baianos, essa responsabilidade ficou a encargo da Associação de Moradores.

Destaca esse mesmo autor que, "sem constrangimentos institucionais, o comportamento egoísta vai impedir trocas complexas, devido à incerteza que a outra parte vai encontrar em seu interesse na aplicação do acordo" (NORTH, 1990, p. 17), motivo pelo qual destacamos aqui o papel da Associação de Moradores do Morro dos Baianos. Para North (1990, p. 17), "todas as sociedades, da mais primitiva à mais avançada, as pessoas impõem constrangimentos umas às outras de forma a estruturar suas relações com os outros", uma vez que os constrangimentos reduzem os custos da interação humana, o que foi importante para que todos os moradores se envolvessem no mutirão.

É certo que outros tipos de constrangimentos foram importantes para a coesão da comunidade no que concerne a participar do mutirão. Aponta North (1990, p. 13) que existem regras informais eficazes na ordenação social e, consequentemente, na produção de um ambiente propício a trocas econômicas. Para ele, "constrangimentos informais também são características sutis das economias modernas". Tais constrangi- mentos informais são frutos da cultura/ história dos indivíduos e desempenham um papel de grande importância. Incitamentos morais e "solidários" ocupam, na realidade, um papel relevante na emergência da ação coletiva. Agir coletivamente em uma coletividade, em que predominam os laços e as redes de solidariedade, de confiança e de amizade, pode constituir uma obrigação moral para o indivíduo, da mesma forma que pode se tornar um prazer. Sob essas condições, é a não participação que será custosa, pois poderá pôr em questão a imagem e a estima que o indivíduo tem de si próprio. Para Oberschall (1973), a ausência de laços e a decomposição das redes de interação são obstáculos importantes à mobilização (ou não incentivo à participação), razão pela qual julgamos que o conceito de Capital Social poderia colaborar para preencher algumas lacunas explicativas.

Buscando, grosso modo, identificar o estoque de Capital Social, realizamos algumas perguntas ligadas às características desse conceito. O intuito foi identificar se a comunidade estudada teria como facilitador da ação coletiva um significativo estoque de Capital Social. Nossa hipótese inicial é de que tal grupo teria se formado movido por interesses individuais, como até aqui os resultados têm sugerido. Incluímos no questionário quantitativo algumas perguntas que acreditamos apontar uma direção interpretativa da existência ou não de estoque desse capital. Tais perguntas se relacionam diretamente à confiança. Os principais resultados encontrados são apresentados na Tabela 2. 
Tabela 2 - Principais resultados encontrados ligados à averiguação de estoque de Capital Social

\begin{tabular}{|c|c|c|c|c|}
\hline \multicolumn{5}{|c|}{ Algumas perguntas ligadas aos indicadores de estoque de Capital Social ${ }^{1}$} \\
\hline $\begin{array}{c}\text { A maioria das } \\
\text { pessoas do } \\
\text { bairro geral- } \\
\text { mente está } \\
\text { disposta a aju- } \\
\text { dar você caso } \\
\text { necessite? }\end{array}$ & $\begin{array}{c}\text { Pode-se confiar } \\
\text { na maioria das } \\
\text { pessoas que } \\
\text { moram neste } \\
\text { bairro? }\end{array}$ & $\begin{array}{l}\text { Em uma situação } \\
\text { de emergência, } \\
\text { como a doença } \\
\text { de um familiar } \\
\text { ou perda de em- } \\
\text { prego, o senhor } \\
\text { acredita que } \\
\text { receberia ajuda? }\end{array}$ & $\begin{array}{c}\text { Julgue a } \\
\text { frase: “Os } \\
\text { políticos } \\
\text { prometem, } \\
\text { depois não } \\
\text { cumprem". }\end{array}$ & $\begin{array}{c}\text { Para resolver } \\
\text { os problemas } \\
\text { do Brasil, o } \\
\text { que considera } \\
\text { melhor? }\end{array}$ \\
\hline $\begin{array}{l}15 \% \text { afirmaram } \\
\text { que sim, e } 65 \% \\
\text { responderam às } \\
\text { vezes. Nenhum } \\
\text { entrevistado dis- } \\
\text { se que nunca. }\end{array}$ & $\begin{array}{l}35 \% \text { afirmaram } \\
\text { que sim, e } 45 \% \\
\text { afirmaram que } \\
\text { às vezes. Apenas } \\
20 \% \text { afirmaram } \\
\text { que não. }\end{array}$ & $\begin{array}{l}65 \% \text { afirmaram } \\
\text { que da família; } \\
\text { apenas } 25 \% \\
\text { afirmaram que } \\
\text { receberiam ajuda } \\
\text { dos vizinhos. }\end{array}$ & $\begin{array}{l}55 \% \text { concor- } \\
\text { dam, e } 45 \% \\
\text { concordam em } \\
\text { parte. Apenas } \\
10 \% \text { discorda- } \\
\text { ram. }\end{array}$ & $\begin{array}{l}75 \% \text { afirmaram } \\
\text { que acham } \\
\text { melhor a parti- } \\
\text { cipação social, } \\
\text { contra } 25 \% \\
\text { que acreditam } \\
\text { ser melhor um } \\
\text { bom líder. }\end{array}$ \\
\hline
\end{tabular}

Fonte: elaborada pelos autores com base nas entrevistas realizadas.

${ }^{1}$ Alguns entrevistados não quiseram ou não souberam responder.

A Tabela 2 aponta a existência de indícios de confiança social entre os indivíduos da comunidade; "ingrediente" fundamental para a ação coletiva. Porém, notamos que tal confiança não é unânime, predominando "às vezes". Essa constatação consolida ainda mais o entendimento de que os indivíduos, de certa forma, confiam nos vizinhos - o que faltava era enxergar as cartas abertas do jogo, isto é, "se houver uma certeza de que os demais participarão, eu também participo", afirmou um dos entrevistados, corroborando com os resultados quantitativos observados.

Notamos, ainda, que o nível de confiança nos políticos é baixo. Em entrevista, alguns moradores afirmaram que foi a descrença no Poder Público que os fizeram "arregaçar as mangas". Afirmaram que a ideia tido início entre eles, de modo que já estavam se unindo para fazer blocos por conta própria. "Aí, a prefeitura ficou sabendo e propôs a parceria", afirmou outro entrevistado.

Podemos, assim, apontar algumas questões identificadas. A comunidade em estudo não possuía um estoque significativo de Capital Social, apenas uma espécie de "confiança desconfia- da", mas que, somada ao interesse individual compartilhado de ter sua rua calçada, à descrença no Poder Público local e à certeza de que todos participariam, tornou possível a ação coletiva, a qual produziu uma sinergia participativa. Ao ver o jogo se processando de forma clara, os moradores sentiram-se seguros para participar, pois estavam certos da inexistência de "caronas".

$\mathrm{O}$ dilema do prisioneiro e o princípio da racionalidade colaboraram, assim, para que compreendêssemos parcialmente o fenômeno social em estudo, embora apresentando algumas limitações explicativas, como o fato de não possibilitar entender as motivações emotivas e culturais que levam os indivíduos a participar de ações coletivas. Algumas lacunas explicativas foram preenchidas pelo conceito de Capital Social e pela alternativa hobbesiana.

\section{Considerações finais}

Este trabalho se enquadra no primeiro momento de uma pesquisa classificada por Coleman (apud AQUINO, 2000 , p. 20) como o "momento inteiramente situado no nível micro, onde 
se dá a compreensão das ações sociais praticadas por indivíduos", mas que nos indica um caminho para o "momento de transição do nível micro para o nível macro, onde se expõe como eventos individuais podem resultar em mudanças sociais" (COLEMAN, 1990 apud AQUINO, 2000, p. 20). No caso em estudo, as ações individuais converteramse em maior estoque de Capital Social, o que nos possibilita apostar que ações racionais individualistas movidas por interesses que se repetem podem gerar uma sinergia capaz de proporcionar condições para futuras ações sociais. Parece que, nesse caso, o jogo repetitivo fornece maior segurança para a participação dos indivíduos.

Como já apontado por Coleman, a TER não possibilitou compreender todas as ações humanas identificadas ou não nos mutirões em estudo, como as relações movidas por afetos, por costumes tradicionais ou por questões morais. Embora a TER apresente limitações referentes a situações altruístas ou motivadas por ações não racionais, ela se mostrou bastante instrumental, como já sinalizado por Elster (1994), para que efetivássemos o presente estudo de caso.

No caso em estudo, interesses individuais converteram-se em interesse coletivo, o que possibilitou a ação coletiva. Mesmo se tratando de ações motivadas por interesses individuais compartilhados, tal comunidade agiu a fim de obter um ganho coletivo. Embora não tivesse sido a situação ótima, ao optar por pagar por alguns custos, a comunidade analisada solucionou um problema antigo de infraestrutura.

Foi identificado que tal ação conjunta criou condições para uma posterior ação social. Assim, observamos que ações racionais individualistas movidas por interesses que se repetem podem gerar uma sinergia capaz de proporcionar condições para futuras ações sociais. Parece que, nesse caso, o jogo repetitivo fornece maior segurança para a participação dos indivíduos.
No caso em estudo, a racionalidade dos indivíduos levou-os a buscar um ganho subótimo, uma vez que a solução ótima seria o Poder Público, tão somente, prover a pavimentação. Devido à observação da repetição do jogo (todo ano o Poder Público promete tais pavimentações, as quais não se materializam), julgaram melhor propor uma parceria à Secretaria de Obras do município para a realização de mutirões (solução subótima). Para que tal ação fosse efetivada, observamos que os utilitaristas, seguidos pelos kantianos, foram importantes para iniciar o novo jogo, dando maiores garantias de que o mutirão iria ser realizado. A Associação de Moradores também colaborou ao tomar a função hobbesiana de exercer coerção sobre os moradores, mas principalmente sobre o Poder Público local.

Acreditamos ter satisfatoriamente atingido os objetivos da presente pesquisa, bem como levantado algumas questões para futuras pesquisas, tal como identificar se essas parcerias geram sinergia participativa que possa se estender a outras áreas da política local.

$\mathrm{Na}$ comunidade estudada, embora não houvesse inicialmente um estoque significativo de Capital Social, a ação coletiva praticada parece ter aberto caminho para futuras ações, uma vez que a confiança foi ampliada. Não esperamos romanticamente que tal comunidade passe a atuar de forma mais intensa nos engajamentos políticos, mas acreditamos que, quando os interesses individuais forem compartilhados, a ação social fluirá, a partir dessa ação, com mais facilidade.

Quanto aos esforços para se apropriar da Teoria dos Jogos e da Teoria da Escolha Racional, identificamos que, tomados os devidos cuidados, tais teorias podem ser mobilizadas a fim de compreender melhor a realidade social. Além disso, notamos que a associação entre essas teorias e o conceito de Capital Social pode trazer elementos que apenas as Teorias em questão não dão conta de explicar. 


\section{Referências}

AQUINO, J. A. de. As teorias da ação social de Coleman e de Bourdieu. Revista Humanidades e Ciências Sociais, vol. $2 \mathrm{n}^{\circ} 2$. p. 17-29, 2000.

BAQUERO, M.; SOUZA, B. M.; SCHERER, R. S. A desconfiança política e sua incidência na fragmentação da cultura política. Rio Grande do Sul, 2010. Anais do seminário Nacional de Ciência Política da UFGRS, 2009. Disponível em: <http://www6.ufrgs.br/ sncp/> Acesso em: 22 de Abril de 2010.

BORGES, A. J. M; VILLELA, T. M. C. (Orgs). Finanças dos Municípios Capixabas. volume 16, Vitória/ES: Aequus Consultoria, Jun. 2010.

BOUDON, R. Effets pervers et ordre sociale. Paris: P.U.F. 1977.

BOURDIEU, P. Le Capital Social. Notes Provisoires. Actes de la Recherche in Sciences Sociales, 31, n. 31, p. 2-3. 1980.

COLEMAN, J. S. Foundations of social theory. Harvard University Press, 1994.

D'ARAUJO, M. C. Capital Social. Rio de Janeiro: Jorge Zahar, 2003.

ELSTER, J. Peças e Engrenagens das Ciências Sociais. Tradução de Antônio Transito. Rio de Janeiro: Relume-Dumará, 1994.

FUKUYAMA, F. Confiança: as virtudes sociais e a criação da prosperidade. Tradução de Alberto Lopes. Rocco: Rio de Janeiro, 1996.

FURLANETTO, E. L. Instituições e desenvolvimento econômico: a importância do capital social. Revista de Sociologia Política. Curitiba, v. 16. Número suplementar. p. 55-67, 2008.

HIGGINS, S. S. Fundamentos Teóricos do Capital Social. Chapecó: Argos, 2005.
MATOS, H. Capital Social e Comunicação: interfaces e articulações. São Paulo: Summus, 2009.

OBERSCHALL, A. Social conflicts and social movements. Englewood Cliffs: Prentice-Hall, 1973.

OLSON, M. A Lógica da Ação Coletiva. Trad. Fabio Fernandez. São Paulo: Edusp, 1999.

PIÚMA, Prefeitura Municipal de Piúma [entrevistas com representantes do Executivo de Desenvolvimento Municipal]. 2011.

PUTNAM, R. D. Comunidade e Democracia: a experiência da Itália moderna. Trad. Luiz Alberto Monjardim. Rio de Janeiro: Editora Fundação Getúlio Vargas, 1996. 